\title{
11. Conceptual Change and Conceptual Diversity Contribute to Progress in Science
}

\author{
Paul Griffiths
}

\begin{abstract}
[W]e must sharpen our conceptual tools as best we can and have faith that in using them to untangle the complexity we shall see how to fashion better ones.
\end{abstract}

— Hinde 1985, 990

Key theoretical constructs are frequently defined in different ways by different practitioners. The idea of a biological species is perhaps the most famous example. The many competing 'species concepts' are the subject of both an enormous literature in biology (Mayden 1997) and a substantial body of commentary in the history and philosophy of science (Wilkins 2009). Such conceptual diversity is often viewed as dysfunctional, leading to miscommunication between practitioners from different fields, making their findings incommensurable with one another, and generally impeding scientific progress. For example, many have argued that the multiple meanings of the term 'innate' impedes progress in understanding behavioural development for these reasons (Mameli and Bateson 2006; Linquist et al. 2011). Similarly, eminent emotion researcher Klaus Scherer has argued that lack of a shared definition of emotion holds back research through the failure to 'define central working concepts in the universal, invariant, and consensual fashion generally required by a systematic scientific approach' (Scherer 2005 696).

In this chapter I want to explore the opposite possibility. The existence of multiple competing definitions of a construct, and the corresponding different conceptions or ways of thinking about that construct can be a functional part of the scientific process. The example I will use to make this point is the gene. In our work on this key biological construct, my collaborators and I argue that constructs like the gene concept exist to serve ongoing projects in which scientists try to derive empirical generalisations of increasing scope and reliability (Stotz et al. 2004, Griffiths and Stotz 2006, 2013). For the scientific practitioner, concepts are tools that classify experience in ways that meet their specific needs and which are reshaped in the light of new empirical findings. This attitude is sometimes made explicit, but is implicit whenever scientists describe a statement as a 'definition' and yet regard it as hostage to future empirical findings, as they commonly do. Practitioners adjust both 
the extension of these concepts, in order to encompass sets of instances with as much in common as possible, and the intension of these concepts, so that statements that were once true by definition become open to empirical testing, and vice versa. If scientific concepts are evolving tools, it should not be the aim of philosophers of science to identify one correct conception associated with a word or phrase. An alternative aim, and the one that we have adopted in our work, is to examine how conceptual differences reflect different scientific requirements. The needs of a particular research field can be conceived as an epistemic 'niche' and changes in the concept over time can be seen as responses to changes in the niche. As a result of such conceptual evolution, what was originally a shared concept between two or more communities of researchers can become a range of related but distinct concepts.

In his discussion of the diversity of emotion definitions Scherer identifies the problem as 'the need to resort to everyday language concepts' and the 'inherent fuzziness and the constant evolution' of such concepts (Scherer 2005, 696). I believe this to be a misdiagnosis. The difference between scientific and everyday concepts does not lie in the precision and stability of the former. The term 'gene' is perhaps the most successful example of the introduction of a new technical term into the life sciences (Johannsen 1909), yet its definition has changed continuously since that introduction and remains highly controversial today. The spectacular success of the molecular biosciences did not require a precise and stable definition of 'gene'. Nor has that success led to a precise and stable definition. Instead, 'we are currently left with a rather abstract, open and generalized concept of the gene, even though our comprehension of the structure and organization of the genetic material has greatly increased' (Portin 1993, 173).

The first person to stress that the categories which 'carve nature at its joints' need not be clearly defined was the Victorian polymath William Whewell (1971, first published 1860). Whewell remarked that science makes rapid progress whenever it discovers 'groups made by nature, not by mere definition', such as the chemical elements and biological species. The ability to define such a category is neither necessary nor sufficient to make it valuable to science. The Aristotelian category of superlunary objects (objects outside the moon's orbit) is precisely defined but scientifically useless. Conversely, the definition of the gene remains controversial, but a vast amount of successful scientific work has been done with that concept.

In the next section, I outline two conceptions of the gene, the Mendelian conception introduced by Johannsen in 1909 and the molecular conception that emerged in the early 1960s through the work of Francis Crick, James Watson, Seymour Benzer, and others. I will show that these two very different ways of thinking about genes coexist in biology even today. The term 'gene' can be 
understood in two different ways by investigators, and sometimes even by the same investigator at different points in a single research project. Although these two ways of thinking often converge on the same sequences of DNA, sometimes they do not, and this need not cause any difficulty for science. My discussion of this example will illuminate how such slippage of meaning can be functional rather than dysfunctional.

\section{The evolution of conceptual diversity in genetics}

The gene as it was conceived in classical Mendelian genetics - the research tradition that flourished in the first half of the twentieth century, before the advent of molecular biology - was not an observable entity, but it was something different from the unobservable entities postulated by earlier particulate theories of inheritance, such as Darwin's 'gemmules' (Darwin 1868). The gene was a practical tool for predicting and explaining the outcome of breeding one organism with another. The gene was not merely postulated to explain the success of Mendelian genetics; it played a key role in the highly successful practice of 'genetic analysis' - analysing the pattern of inheritance between organisms and using these analyses to answer all sorts of biological questions, from Thomas Hunt Morgan's discovery of chromosomal sex determination (Morgan 1917) to Muriel Wheldale's pioneering studies of plant pigments (Wheldale 1916).

Geneticists certainly hoped that the gene would be shown to exist as a physical reality within the cells of the organism. But the practical role of the gene in genetic analysis meant that the gene would remain an important and legitimate idea even if this did not work out. Morgan remarked in his Nobel Prize acceptance speech that 'at the level at which the genetic experiments lie, it does not make the slightest difference whether the gene is a hypothetical unit, or whether the gene is a material particle'. ${ }^{1}$ When Morgan contrasted a 'hypothetical unit' to a 'material particle' I believe that he was envisaging something like a centre of mass in physics. When two bodies act on one another, for example by being at the two ends of a lever, their masses are distributed throughout each body. But when we calculate how the bodies will affect one another, the whole mass is assigned to a single, infinitesimal point - the centre of mass. The centre of mass is not a material particle, but every object has a centre of mass. In the same way, even if there were no straightforward material particles corresponding to genes, genes could still play a critical role in the calculus of heredity.

1 Morgan, TH (1933) Nobel lecture, nobelprize.org/nobel_prizes/medicine/laureates/1933/morgan-lecture. html, retrieved 29 January 2011. 
Historian of genetics Raphael Falk $(1984,2009)$ described this situation by saying that the gene of classical Mendelian genetics had two separate identities. One identity was as a hypothetical material unit of heredity, and some genetic research was directed to confirming the existence of these units and finding out more about them. But the gene had a second, and more important, identity as an instrument used to do biology. The future development of genetics was the result of the interplay between these two identities.

The continued development of genetic analysis, and particularly the work of Seymour Benzer which showed the need to distinguish the unit of genetic function from the units of mutation and recombination (Benzer 1957), combined with Francis Crick and James Watson's work on the structure (Watson and Crick 1953) and function (Crick 1958) of DNA to produce a new, molecular conception of the gene as a distinctive kind of DNA sequence. This is the gene presented in biology textbooks today.

Each gene has a promoter region that acts as a signal to the machinery that transcribes the DNA into RNA. This is followed by an open reading frame, a series of nucleotides that correspond to the series of RNA codons that specify the amino acids in a protein, beginning with a start codon and ending with a stop codon. The gene of molecular biology is thus a linear image of a gene product - an RNA or a protein - in the DNA. ${ }^{2}$

The fact that molecular genes are defined in such a way that the nucleotide sequence of a gene has a linear correspondence to the sequence of its products is the key to the practical utility of the molecular gene concept in research and in biotechnology. It is the basis of most of the techniques, whether chemical or computational, by which biologists identify and manipulate those molecules. This is true despite the extent to which transcriptional and post-transcriptional processes can distort this relationship in multicellular organisms. As Karola Stotz and I have argued, the fact that the 'picture' of the product in the DNA is sometimes a cubist picture does not stop biologists from figuring out the relationship between DNA and product (Griffiths and Stotz 2007, 2013).

Today the molecular, material identity of the gene is the most prominent, but not because Mendelian conception of the gene was shown to be in error and replaced. Instead, as I will now show, the Mendelian conception continues to exist alongside the molecular conception and plays a critical role in research to this day.

2 I owe this expression to Rob D Knight. 
The emergence of the molecular conception of the gene appears to be a successful example of the research strategy of identifying a causal role and seeking the concrete occupant of that role (Lewis 1966). In this case, the role was that of the Mendelian gene, something whose distinctive pattern of transmission from one generation to the next explains many of the phenomena of heredity. It is natural to suppose that the occupant of that role turned out to be the molecular genean open reading frame with an adjacent promoter region. But the relationship is not that simple. The role-occupant framework for thinking about conceptual change starts from the observation that some concepts can be analysed using the causes and effects of the thing being conceptualised (its 'causal role'). Lightning was originally known only as something that causes bright flashes in the sky during thunderstorms and whose destructive effects we see as lightning strikes. When it was shown that the flashes and destructive strikes are the effects of atmospheric electrostatic discharges, it followed necessarily that lightning is atmospheric electrostatic discharge.

This framework seems on first inspection to describe what happened in the transition from Mendelian to molecular genetics: with the unravelling of the genetic code and of the basic processes of transcription and translation in the 1960s, the two identities of the gene in classical genetics - the Mendelian and the hypothetical material - converged on a single identity, the molecular gene. Looked at more closely, however, the causal role of the gene had been significantly revised to take account of findings about the material gene. In classical Mendelian genetics, the gene played three theoretical roles. It was the unit of mutation: changes in genes give rise to new, mutant alleles of the same gene. It was also the unit of recombination: crossover between chromosomes either separates genes that were previously linked or links genes that were previously inherited independently. Finally, the gene was the unit of function: the genotype that interacts with the environment to produce the phenotype is a collection of genes, and any effect of genotype on phenotype can be traced back to some gene or combination of genes.

It was natural to project these ideas from Mendelian genetics onto the gene as a hypothetical material entity and to expect that the material gene would be a unit of mutation, of recombination, and of genetic function. But the new, molecular concept of the gene did not live up to that expectation. A mutation is something that can happen to any stretch of the DNA molecule, not only to genetically meaningful units such as molecular genes. Recombination is a highly regulated process involving chromosomes and an accompanying cast of enzymes. In analysing this process, there is no need to divide the DNA itself into 'units of recombination'. Recombination can occur within a molecular gene so that one part of one allele is recombined with the complementary part from its sister allele, as well as occurring between whole alleles, and it can occur between 
segments of DNA that are not molecular genes at all. So the new conception of the molecular gene was one in which the gene is only the unit of function and not the unit of mutation or recombination. While the molecular conception of the gene grew out of the earlier conception, it did not do so by the discovery of a material unit that fulfilled the role of the Mendelian gene.

In the light of these observations about the development of the gene concept, I can now explain why the Mendelian conception of the gene persists alongside the molecular conception, rather than being reduced to it as lighting was reduced to atmospheric electrostatic discharge. The concept of the molecular gene applies only to sequences that have a structure something like that described above and that act as the template for making a gene product. But in humans, for example, only 1 per cent to 2 per cent of the DNA consists of sequences used to make proteins. Some - currently controversial-proportion of the remaining sequence is used to make functional RNAs. But much of the sequence is not transcribed to make a product, and does not have the structural features, such as promoter regions, which make transcription possible. There are many segments of chromosome that have some effect on the phenotype and hence behave as Mendelian alleles but that do not count as genes under the new molecular conception. Any difference in the sequence of DNA that causes a difference in phenotype will function as a Mendelian allele, but it need not be an allele of any molecular gene.

It would be foolish to redefine allele in a way which restricts the term to alleles of molecular genes, because the fact that these other sequences are behaving as Mendelian alleles is not something to gloss over. If there is an inherited cause of phenotypic differences, we want to know about it! Conversely, the molecular gene cannot be redefined as any piece of DNA that can act as a Mendelian gene, because this would render it unsuitable for the purpose for which it is used in molecular biology - namely, to identify sequences that have a linear correspondence to the biomolecules made from the DNA.

These observations would be a mere quibble if the possibility of the two conceptions coming apart were merely theoretical, or even if it were very rare. But this is not the case. There are many other ways that DNA sequences can play a role in the development of phenotypes besides acting as linear templates for the synthesis of biomolecules. When one of these other pieces of DNA comes in two or more forms with different phenotypic effects, they will behave as Mendelian alleles and can be investigated via genetic analysis. Even if they are not called genes, they are treated as (Mendelian) genes, and sometimes they are called genes but only when speaking in an appropriate context. Such is the flexibility of scientific language. For example, when a medical geneticist is seeking the 'genes' for a disorder, she is looking for Mendelian alleles: sections of chromosome whose inheritance explains the phenotypic differences observed 
in patients. Translated into molecular terms, these sequences may or may not turn out not to be molecular genes. It is entirely possible that they will be segments of DNA that fulfil other, regulatory functions.

A clear example of the continuing coexistence of the Mendelian and molecular identities of the gene comes from studies of the gene Lmbrl in the mouse and its homologue on human chromosome seven (Lettice et al. 2002). This locus is known to house an allele that produces abnormal limb development in both mice and humans. But further molecular analysis of that locus shows that the molecular gene within which the mutation is located is not a molecular gene that plays a role in the development of these abnormalities. Instead, there is a sequence embedded in a non-coding stretch within that gene that acts to regulate the gene 'sonic hedgehog' $(s h h)$.

The gene shh is located about one million DNA nucleotides away on the same chromosome and is known to be important in limb development. The regulatory sequence at the original locus is called an 'enhancer' in molecular genetics, not a gene, since it does not code for a product. It is not a functional component of the molecular gene within which it is physically located, since this mutation does not affect the product of that gene or the post-transcriptional processing of that product. But this mutated regulatory sequence is the Mendelian allele for the abnormal limb development. Conversely, shh is a paradigmatic molecular gene, but there exists no allele of shh that causes (is the Mendelian allele for) this kind of abnormal limb development. What is happening here is that in one experimental context - that of hunting for the mutation responsible for the phenotype - the idea of gene assumes its Mendelian identity, while in the other context - that of analysing the DNA sequence - the idea of gene assumes its molecular identity. These two identities of the gene often converge on the same sequence of DNA, but sometimes they do not.

The relationship between Mendelian and molecular conceptions of the gene defies at least the simplest form of the role-occupant analysis of scientific progress that I described above. Biologists were looking for the physical occupant of the role of the Mendelian gene. But what they found, and what molecular geneticists call a gene, occupies only part of that role, and the original role remains important, too. Molecular biology enriched genetics with a new way of thinking about genes, and biologists today have both these ways of thinking about genes in their toolkit. They move smoothly between these two contextually activated representations of genes as they move from one research context to another. 


\section{The function of conceptual diversity in genetics}

The case of Mendelian and molecular genetics shows how conceptual diversity can be a functional part of scientific practice. The two conceptions of the gene are tools used to do different kinds of scientific work. One is used in genetic analysis to locate the pieces of DNA that make a difference to some phenotype. The other is used to identify pieces of DNA that play one specific role in the production of gene products - that of the template for transcription. Both ideas are useful and neither can be replaced by the other.

One suggestion might be that the term 'gene' should be reserved for one sense and another term introduced for the other sense. This kind of stipulation may sometimes be useful. However, one of these two ideas developed out of the other, and during the period in which this was happening the effect of demanding that the term be used only in accordance with one definition would have been stifling. It would have prevented the emergence of a new meaning in response to the needs of a particular kind of experimental practice. Scientists need to be able to flexibly redefine theoretical constructs to fit the phenomena they are uncovering. But sometimes, when different groups are studying different phenomena, they need to redefine them in different ways. At the end of such a process it may be possible to distinguish the two constructs and give them separate names. But the period when productive conceptual innovation is happening is precisely the period when this cannot be done, both because the two ways of thinking have not yet been clearly distinguished and because it is not yet clear that there are two different phenomena that need to be distinguished.

Even when two or more different conceptions of a construct have emerged, it is not clear that stipulating that a term be used in only one sense can be more than a temporary expedient to ensure clarity in a particular paper or in a particular program of research. Scientific change is not a series of discrete steps, but a continuous process. As well as major events of 'conceptual speciation' there are minor local variants that arise and die out again, as scientists explore possible ways to think about a topic. It is by stretching and warping constructs in this way that science hits on novel and productive ways of classifying nature.

\section{Dysfunctional conceptual diversity}

But while conceptual diversity can be functional, it is not always so. In the paper discussed in my introduction, Scherer (2005) argued that the continuous interchange between the language of psychology and vernacular language is a 
fundamental problem for emotion theory. This may be correct, but I suggest the problem is not that ordinary language transmits its imprecision to the language of science. The real problem is more or less the opposite. The ties between scientific and ordinary usage prevent concepts from evolving to meet the needs of scientists.

This dysfunctional pattern can be seen with the idea of innateness. It is a truism that the term 'innate' is vague and ambiguous. According to ethologist Patrick Bateson (1991),

At least six meanings are attached to the term: present at birth; a behavioral difference caused by a genetic difference; adapted over the course of evolution; unchanging throughout development; shared by all members of a species; and not learned.

More recently Matteo Mameli and Bateson systematically reviewed the scientific use of the term 'innate' and identified no less than 26 proposed definitions. They judged eight of these to be both genuinely independent definitions and potentially valuable scientific constructs (Mameli and Bateson 2006).

The work that my collaborators and I have conducted on the concept of innateness suggests that this ambiguity leads to unproductive slippage of meaning because the use of the term 'innate' cannot evolve freely into any specific scientific niche. This is because it is strongly anchored in a vernacular conception of innateness that conflates the various different constructs that could each be of scientific value in their own right (Griffiths 2002, Griffiths and Machery 2008, Griffiths et al. 2009, Linquist et al. 2011).

What is the vernacular conception of innateness? Just as there are commonsense ideas about heat and about dynamics, ideas which formal education wholly or partially replaces with scientific conceptions of these domains (Clement 1983, McCloskey 1983), there are commonsense ideas about biology, ideas commonly referred to as 'folk-biology' (Atran 1990, Medin and Atran 1999). Prominent amongst these is the idea that some traits are expressions of the inner nature of animals and plants, whilst other traits result from the influence of the environment. The idea that living things have inner natures that make them the kind of organism that they are is intimately linked to the very idea of heredity. The hereditary traits of an animal are those that are passed on as part of its nature. Natures also explain the stability of some traits within a single lifetime-people do not expect a black sheep to grow white wool after shearing, because the colour of its wool is part of its nature. Like 'folk physics', these 'folk-biological' ideas work reasonably well for hunting, farming, and traditional stockbreeding. 
Griffiths (2002) hypothesised that the vernacular concept of innateness is an expression of an implicit theory that organisms possess inherited 'inner natures' (1) that cause them to possess species-typical properties, (2) whose development is resistant to environmental influences, and (3) that are functional (they have a purpose). That is, when biologically naive subjects believe a trait is innate, they believe that it is an expression of an organism's inner nature, and hence that the trait will possess all or some combination of the three features of species typicality, developmental fixity, and purposive function. We have given these three factors the more convenient labels typicality, fixity and teleology, and we understand each as a broad, conceptual theme:

- Typicality - the trait is part of what it is to be an organism of that kind; every individual has it, or every individual that is not malformed, or every individual of a certain age, sex or other natural subcategory.

- Fixity - the trait is hard to change; its development is insensitive to environmental inputs in development; its development appears goaldirected, or resistant to perturbation.

- Teleology - this is how the organism is meant to develop; to lack the innate trait is to be malformed; environments that disrupt the development of this trait are themselves abnormal.

Using vignettes of behavioural development we showed that manipulating information about these three factors predicts a substantial amount of the variance in a subject's willingness to classify the resulting behaviour as innate. We also showed that there is no interaction amongst the three factors, which we interpret to mean that our subjects understand all three as independent signs that the behaviour flows from the animal's inner 'nature' (Griffiths et al. 2009). In a series of further studies we replicated these results and extended them to elucidate what biologically naive subjects mean when they describe behaviour as 'in the DNA' (Linquist et al. 2011). So we now have some empirical warrant for our claim that the vernacular concept of innateness is driven by these three independent criteria.

There have been several attempts to clarify the concept of innateness by stipulation. Unsurprisingly, most of these pick one of the three features just discussed and stipulate that this alone is to be meant by 'innate'. One approach identifies innate traits with those characteristic of an entire species and acquired traits with those that vary between populations and individuals, the factor we call typicality (e.g. Stich 1975). A second approach identifies innate traits with those that can be explained by natural selection, the factor we call teleology (e.g. Lorenz 1966). A third distinguishes two different patterns of interaction between genes and environment and identifies one pattern with the innate and another with the acquired. This defines innateness as the factor we call fixity (e.g. Ariew 2006). 
We have also found that scientists who subscribe to one of these stipulative definitions nevertheless continue to respond to our manipulations of the other factors that are part of the vernacular conception of innateness when classifying behaviour as innate or acquired. The entrenched, vernacular understanding resists the scientific imperative for the concept to evolve to represent only one of the potentially valuable constructs confounded in the vernacular conception.

\section{Conclusions}

1. Conceptual change in science can be understood as the evolution of constructs to fit a changing epistemic niche. This evolution is driven by the need of scientists to group phenomena together in ways that facilitate reliable inductive generalisation. On occasion this can result in conceptual 'speciation' in which a construct evolves into two or more distinct constructs.

2. The adoption of stipulative definitions can only ever be a temporary expedient. Efforts to rigorously police scientific usage would be dysfunctional because they would prevent scientific concepts from exploring new niches.

3. Another factor that can obstruct conceptual evolution is the existence of an entrenched intuitive conception which obstructs the emergence of new conceptions to serve specific scientific purposes.

\section{Acknowledgements}

This research was supported under Australian Research Council's Discovery Projects funding scheme (project number DP0878650).

\section{References}

Ariew, A (2006) Innateness. In Matthen, M and Stevens, C (eds) Handbook of the philosophy of science. Elsevier, Amsterdam: 567-84.

Atran, S (1990) Cognitive foundations of natural history: towards an anthropology of science. Cambridge University Press, Cambridge.

Bateson, PPG (1991) Are there principles of behavioural development? In Bateson, PPG (ed.) The development and integration of behaviour: essays in honour of Robert Hinde. Cambridge University Press, Cambridge: 19-39. 
Change!

Benzer, S (1957) The elementary units of heredity. In McElroy, WD and Glass, B (eds) A symposium on the chemical basis of heredity. Johns Hopkins Press, Baltimore: 70-133.

Clement, J (1983) A conceptual model discussed by Galileo and used intuitively by physics student. In Gentner, D and Stevens, AL (eds) Mental models. Erlbaum, Hillsdale NJ: 325-40.

Crick, FHC (1958) On protein synthesis. Symposia of the Society for Experimental Biology 12: 138-63.

Darwin, CR (1868) The variation of animals and plants under domestication. John Murray, London.

Falk, R (1984) The gene in search of an identity. Human Genetics 68: 195-204.

Falk, R (2000) The gene: a concept in tension. In Beurton, P, Falk R and Rheinberger, H-J (eds) The concept of the gene in development and evolution. Cambridge University Press, Cambridge: 317-48.

Griffiths, PE (2002) What is innateness? The Monist 85(1): 70-85.

Griffiths, PE and Machery, E (2008) Innateness, canalisation and 'biologicizing the mind'. Philosophical Psychology 21(3): 397-414.

Griffiths, PE, Machery, E and Linquist, S (2009) The vernacular concept of innateness. Mind and Language 24(5): 605-630.

Griffiths, PE and Stotz, K (2006) Genes in the postgenomic era. Theoretical Medicine and Bioethics 27(6): 499-521.

Griffiths, PE and Stotz, K (2007) Gene. In Ruse, M and Hull, D, eds Cambridge companion to philosophy of biology. Cambridge University Press, Cambridge: 85-102.

Griffiths, PE and Stotz, K (2013) Genetics and philosophy: an introduction. Cambridge University Press, New York.

Hinde, RA (1985) Was 'the expression of emotions' a misleading phrase? Animal Behaviour (33): 985-92.

Johannsen, W (1909) Elemente der exakten erblichkeitslehre. Gustav Fischer, Jena.

Lettice, LA, Horikoshi, T et al. (2002) Disruption of a long-range cis-acting regulator for Shh causes preaxial polydactyly. Proceedings of the National Academy of Sciences 99(11): 7548-53. 
Lewis, DK (1966) An argument for the identity theory. Journal of Philosophy 63(1): 17-25.

Linquist, S, Machery, E, Griffiths, PE and Stotz, K (2011) Exploring the folkbiological conception of human nature. Philosophical Transactions of the Royal Society B 366: 444-53.

Lorenz, KZ (1966) Evolution and the modification of behaviour. Methuen \& Co, London.

Mameli, M and Bateson, PPG (2006) Innateness and the sciences. Biology and Philosophy 21(2): 155-88.

Mayden, RL (1997) A hierarchy of species: the denouement in the saga of the species problem. In Claridge, MF, Dawah, HA and Wilson, MR (eds) Species: the units of biodiversity. Chapman \& Hall, New York: 382-423.

McCloskey, M (1983) Intuitive physics. Scientific American 248: 122-30.

Medin, D and Atran, S (eds) (1999) Folkbiology. MIT Press, Cambridge MA.

Morgan, TH (1917) The theory of the gene. American Naturalist 51: 513-44.

Portin, P (1993) The concept of the gene: short history and present status. The Quarterly Review of Biology 68 (2): 173-223.

Scherer, KR (2005) What are emotions? And how can they be measured? Social Science Information 44(4): 695-729.

Stich, S (1975) Innate Ideas. University of California Press, Los Angeles.

Stotz, K, Griffiths, PE and Knight, R (2004) How scientists conceptualise genes: an empirical study. Studies in History and Philosophy of Biological and Biomedical Sciences 35(4): 647-73.

Watson, JD and Crick, FHC (1953) Molecular structure of nucleic acids: a structure for deoxyribose nucleic acid. Nature 171: 737-8.

Wheldale, M (1916) The anthocyanin pigments of plants. Cambridge University Press, Cambridge.

Whewell, W (1971, first published 1860). On the philosophy of discovery. Burt Franklin, New York.

Wilkins, JS (2009) Species: a history of the idea. University of California Press, Berkeley. 
This text is taken from Change! Combining Analytic Approaches with Street Wisdom, edited by Gabriele Bammer, published 2015 by ANU Press, The Australian National University, Canberra, Australia. 